\title{
Programa de Educação pelo Trabalho para a Saúde: formação baseada nos pressupostos das Diretrizes Curriculares Nacionais
}

\author{
Elisa Ribeiro de Oliveira*, Lucimar Aparecida Britto Codato**, Suely Tsuha Massaoka**, \\ Mariana Gabriel***

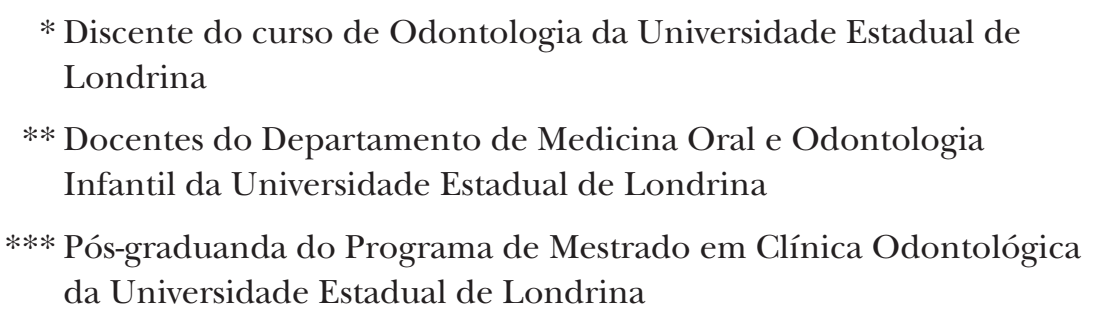

\section{RESUMO}

Este trabalho objetiva correlacionar os pressupostos das Diretrizes Curriculares Nacionais (DCN) para o curso de Odontologia com as atividades desenvolvidas por alunos de Odontologia, integrantes do Programa de Educação pelo Trabalho para a Saúde (PETsaúde) da Universidade Estadual de Londrina (UEL). As DCN apontam que a formação profissional deve estar atrelada às necessidades da população, daí a necessidade da diversificação dos cenários de práticas e do fortalecimento da parceria e da interação entre ensino-serviço e comunidade. Nesta integração, os benefícios são bilaterais, pois formam-se profissionais com perfil adequado às necessidades dos serviços e o processo ensino-aprendizagem acontece nos espaços onde ocorrem as práticas de saúde, que favorecem a formação de futuros profissionais com mais conhecimento e comprometimento para o enfrentamento das reais necessidades de saúde da população. Neste contexto, o PET-Saúde muito contribui para esta integração e, consequentemente, para a implementação das DCN porque possibilita que o discente pratique o conteúdo aprendido na graduação, por meio do trabalho em diversificados cenários de práticas, incentivando-o a pesquisar, trabalhar em equipes multiprofissionais, desenvolver a comunicação, a reflexão, gerenciar serviços e tomar decisões, sempre contextualizadas a realidade que o aluno está inserido e vivenciando no dia-dia dos serviços de saúde.

\section{DESCRITORES}

Educação em Odontologia. Sistema Único de Saúde. Formação de Recursos Humanos.

(2) rimeiramente, para esclarecimento, a autora principal desse estudo, graduanda em Odontologia pela Universidade Estadual de Londrina (UEL), integrante do Programa de Educação pelo Trabalho para a Saúde (Pet-saúde) da UEL, por meio de leituras visando a escolha de tema para o Trabalho de Conclusão de Curso (TCG), identificou a relação entre os pressupostos das Diretrizes Curriculares Nacionais (DCN) com os trabalhos desenvolvidos pelo PETSaúde que motivaram este estudo que busca correlacionar os pressupostos das DCN com as atividades desenvolvidas no Pet-saúde.

Na Odontologia, o modelo de formação sempre foi voltado para a prática liberal, com ênfase na necessidade de aperfeiçoamento e especialização em áreas exclusivamente técnicas. ${ }^{1}$ Porém, essa formação especialista e curativa se distancia cada vez mais do modelo assistencial de saúde vigente no país, no qual se procura a prevenção, a promoção e a assistência à saúde, sempre atreladas à realidade vivenciada pela população. $^{2}$

Para o enfrentamento dessa realidade, verificouse a necessidade de buscar melhorias na formação profissional, por meio de currículos com princípios mais integradores, baseados em temas geradores ou complexos, que funcionassem como eixos transversais, com o objetivo de formar cidadãos conscientes, 
éticos, autônomos, críticos e transformadores. ${ }^{3}$

Logo, a reestruturação do currículo odontológico é necessária para a formação de profissionais que voltem a sua práxis às necessidades requeridas pelo quadro epidemiológico, em meio à historicidade do processo saúde-doença-cuidado. ${ }^{4}$ Para tanto, é necessário repensar o processo ensino-aprendizagem, tanto sob o aspecto dos conteúdos programáticos ("o que" ensinar) como dos processos de ensino ("como" ensinar)..$^{5}$

É fato que uma prática educativa humanizada na área da Saúde coloca o homem como centro do processo de construção da cidadania, comprometida e integrada à realidade social e epidemiológica, às políticas sociais e de saúde, oportunizando a formação profissional contextualizada à realidade da população que busque a resolução e o enfrentamento das necessidades identificadas. ${ }^{6}$

Procurando atender às necessidades dos usuários do Sistema Único de Saúde (SUS) e também à observância dos seus princípios de universalidade, equidade e integralidade, o Ministério da Educação e as Comissões de Especialistas de Ensino elaboraram as DCN, almejando auxiliar a formação acadêmica atrelada a referenciais epidemiológicos, sociais, econômicos e culturais de seu meio, com o propósito de dirigir a sua atuação para a transformação dessa realidade em benefício da sociedade.

Neste contexto, a implantação das DCN foi fundamental para a reorientação da formação profissional, porque apontou a necessidade dos cursos da área da saúde incorporarem aos seus projetos pedagógicos o arcabouço teórico do SUS, com valorização dos postulados éticos e da cidadania, que favorecem a formação profissional de acordo com referenciais nacionais e internacionais de qualidade. ${ }^{7}$

As DCN sinalizam a necessidade de maior integração entre ensino e serviços de saúde e configuram-se como elemento de convergência entre os setores de saúde da educação. Nesta integração, os benefícios são bilaterais, pois formam-se profissionais com perfil adequado às necessidades dos usuários e dos serviços e o processo ensino-aprendizagem acontece nos espaços onde ocorrem as práticas de saúde, o que favorece a formação de futuros profissionais mais sensíveis, com mais conhecimento e comprometimento para o enfrentamento das reais necessidades de saúde da população, pois o aluno tem a oportunidade de vivenciar e participar do dia-dia dos serviços. ${ }^{8,9,10}$

Neste momento, era fato que não se esperavam transformações espontâneas das Instituições de Ensi- no Superior (IES) na direção assinalada pelo SUS, sem que houvesse estímulos adicionais que favorecessem avanços das IES na formação profissional que facilitassem o alcance dos objetivos propostos, em busca de uma atenção à saúde mais equânime, de qualidade, atrelada às necessidades de cada população específica. ${ }^{11}$

Para auxiliar o suprimento dessa demanda, foram lançados no Brasil o Programa Nacional de Reorientação da Formação Profissional em Saúde e o Programa de Educação pelo Trabalho para a Saúde (Petsaúde) que apóiam técnica e financeiramente os cursos de graduação que se dispuseram a realizar mudanças no processo de formação profissional. Tais programas objetivam a integração ensino-serviços, contribuem para a formação profissional e favorecem a implementação das DCN. ${ }^{12,13,14}$

Neste sentido, o Pet-saúde muito tem auxiliado a formação profissional, pois nele os alunos têm a oportunidade de praticar o que é preconizado nas DCN: aprender a aprender, que engloba aprender a ser, aprender a fazer, aprender a viver juntos e aprender a conhecer, favorecidos pela integração ensino serviços e comunidade.

Como consequência desses avanços na formação profissional, espera-se melhorias na integralidade da atenção, na qualidade e humanização do atendimento prestado à população. ${ }^{15}$

Importante destacar que os objetivos gerais propostos pelas Diretrizes Curriculares Nacionais: atenção à saúde, tomada de decisões, comunicação, liderança, administração e gerenciamento e educação permanente $^{15,16}$ estão sendo praticados pelos alunos do Pet-Saúde da UEL, em atividades que possibilitam aos discentes a integração com os serviços de saúde, por meio da prática e da utilização do conhecimento que vem sendo adquirido na graduação, contextualizado à realidade vivenciada pelos alunos nos diferentes espaços onde se produz saúde. Desta forma, o aluno interage com a comunidade praticando atenção à saúde e comunicação, participa de programas sociais, de pesquisas científicas, trabalha em equipes multiprofissionais, que incluem discentes de outros cursos da saúde e também profissionais da rede de serviços.

Neste sentido, segundo Segura et al. ${ }^{17}$ as atividades extramuros favorecem a formação profissional por meio da articulação, integração com os serviços de saúde e da inserção dos alunos na realidade contextual da população. Tais atividades possibilitam aos acadêmicos o conhecimento das estruturas organiza- 
cionais, administrativas, gerenciais e funcionais dos serviços públicos de saúde; a participação no atendimento à população; a compreensão das políticas públicas de saúde e do papel do profissional de saúde e o conhecimento dos parâmetros e instrumentos de planejamento utilizados nos projetos de saúde. ${ }^{17}$

Junior et al..$^{18}$ complementam que as atividades extramurais são importantes para o processo educativo, cultural e científico porque articulam ensino e pesquisa de forma indissociável e viabilizam a ação transformadora entre a universidade e a sociedade, porque favorecem a formação de um futuro profissional comprometido com a realidade social.

\section{CONCLUSÃO}

As atividades desenvolvidas pelos alunos do Petsaúde da UEL estão em consonância com os pressupostos das DCN, o que aponta a relevância desse projeto para a formação profissional atrelada às necessidades da população. Além disso, o PET-saúde tem favorecido a integração ensino-serviço que, além de preconizada pelas DCN, é fundamental para o desenvolvimento das competências requeridas pelas DCN.

\section{ABSTRACT}

Education Program through Health Work: training based on the assumptions of the National Curriculum Guidelines

This study aims to correlate the underlying assumptions of the National Curriculum Guidelines (DCN) for the Dentistry Course with the activities developed by Dentistry students, members of the Education Program through Health Work (PETHealth) of the State University of Londrina. The DCN suggest that professional education should be geared to the needs of the population; hence there is a need for diversification of practical scenarios, for the strengthening of partnerships and for interaction between teaching, service and community. In this integration, the benefits are bilateral; professionals with a profile suited to the needs required for services are trained, and the teaching-learning process occurs in spaces where there are health practices, which favor the training of future professionals with greater knowledge and commitment to face the real health needs of the population. In this context, PET-Health has contributed to this integration and consequently to the implementation of the DCN, because it allows the student to practice the contents learned in college, by working in many spaces of practice, encourag- ing him to research, work in multidisciplinary teams, develop communication and reflection, manage services and make decisions.

\section{DESCRIPTORS}

Dental Education. Unified Health System. Human Resources Formation.

\section{REFERÊNCIAS BIBLIOGRÁFICAS}

1. Garbin CAS, Saliba NA, Moimaz SAS, Santos KT. O papel das universidades na formação de profissionais na área da saúde. Revista da Abeno 2006; 6(1): 6-10.

2. Brasil. Ministério da Saúde. Apresentação. Acesso em 10/06/2011. Disponível em: http://portal.saude.gov.br/portal/saude/cidadao/visualizar_texto.cfm?idtxt= 29178\&janela $=1$

3. Moreira AFB. Propostas alternativas: limites e avanços. Educ Soc 2000;21 (73):109-38

4. Paim JS, Almeida Filho N. Saúde coletiva: uma "nova saúde pública" ou campo aberto a novos paradigmas? Rev Saúde Pública 1998;32(4):299-316.

5. Aquilante AG, Tomita NE. O estudande de Odontologia e a educação. Revista da Abeno 2005; 5(1): 6-11.

6. Pelissari LD, Basting RT, Flório MT. Vivência da realidade: o rumo da saúde para a Odontologia. Revista Abeno 2005; 5 (1) $32-9$.

7. Haddad AE, Morita MC, Pierantoni CR, Brenelli SL, Passarella T, Campos FE. Formação de profissionais de saúde no Brasil: uma análise no período de 1991 a 2008. Rev Saúde Pública 2009. Disponível em: www.scielo. br/rsp

8. Morita, MC; Kriger,L. A relação ensino e serviços de saúde. IN Perri de Carvalho, AC; Kríger, L. (org). Educação Odontológica. São Paulo: Artes Médicas, 2006.

9. Morita, M.C.; Kríger, L. Perri de Carvalho, A.C.; Haddad,A.E. Implantação das Diretrizes Curriculares Nacionais em Odontologia. Dental Press: Maringá, 2007

10. Moyses, S.T.; Kriger,L.; Moyses, S.J. (org). Saúde Bucal das Famílias: trabalhando com evidências. São Paulo: Artes Médicas, 2008

11. Brasil. Ministério da Educação e Ministério da Saúde. Programa de Reorientação da Formação Profissional em Saúde PRÓSAÚDE. 2005. Acesso em 19/06/2011. Disponível em: http:// bvsms.saude.gov.br/bvs/publicacoes/pro_saude1.pdf

12. Brasil, Ministério da Saúde. Ministério da Educação. Programa Nacional de Reorientação da Formação Profissional em SaúdePró-saúde. Objetivos, Implementação e Desenvolvimento Potencial. Brasília: Ministério da Saúde, 2007

13. Brasil, Ministério da Saúde. Programa Nacional de Educação pelo Trabalho para a Saúde-PET-SAÚDE. Acesso em 10/09/10. Disponível em: www.saude.gov.br/porta/SGTES.

14. Pereira, A. C. (org) Tratado de Saúde Coletiva em Odontolo- 
Programa de Educação pelo Trabalho para a Saúde: formação baseada nos pressupostos das Diretrizes Curriculares Nacionais • Oliveira ER, Codato LAB, Massaoka ST, Gabriel M

gia. Nova Odessa: Napoleão, 2009.

15. Brasil. Ministério da Educação e Cultura. Conselho Nacional de Educação. Parecer CNE/CES 1300/01. Diário Oficial da União, Brasília, 06 nov 2001. Acesso em 10/09/10. Disponível em: http://portal.mec.gov.br/cne/arquivos/pdf/CES1300.pdf

16. Brasil, Ministério da Saúde. Programa Nacional de Educação pelo Trabalho para a Saúde - PET-SAÚDE. Acesso em 11/07/2011. Disponível em: http://portal.saude.gov.br/portal/saude/profissional/visualizar_texto.cfm?idtxt= 32566 .

17. Segura MEC, Soares MS, Jorge WA. Programas extramuros nas instituições de ensino de odontologia na América Latina e nos Estados Unidos da América. Contribuição ao estudo. Educ. méd. salud. 1995;29(2):218-27.

18. Júnior AM, Alves MSCF, Nunes JP, Costa ICC. Experiência extramural em hospital público e a promoção da saúde bucal coletiva. Rev Saúde Publica 2005;39(2):305-10.

Recebido em 07/07/2011

Aceito em 25/07/2011 